\title{
An in-depth study on noncovalent stacking interactions between DNA bases and aromatic drug fragments using DFT method and AIM analysis: conformers, binding energies, and charge transfer
}

\author{
Hossein Azizi Toupkanloo ${ }^{1} \cdot$ Zoha Rahmani $^{2}$
}

Received: 1 December 2017/ Accepted: 19 January 2018/Published online: 3 February 2018

CC The Korean Society for Applied Biological Chemistry 2018

\begin{abstract}
This work is aimed at providing physical insights about the $\pi-\pi$ stacking interactions of some popular drug fragments (DF) including indole (I), benzothiophene (Bt), benzofuran $(\mathrm{Bf})$ and guanine $(\mathrm{G})$, adenine $(\mathrm{A})$, A-thymine (AT), G-cytosine (GC) base pairs using density functional theory (DFT), the atoms in molecule (AIM) theory, and natural bond orbital (NBO) analysis. Several stable conformers of present molecules and complexes were optimized at the M062X/6-311++G(d,p) level of theory. The result shows that the IG1 (see the notation below) and IA6 have maximum interaction energy in all of the two G-based and A-based conformers; and order of the adsorption strength is IG1 $>$ BtG6 $>$ BfG1 for G-based complexes and IA6 $>$ BtA6 $>$ BfG6 for A-based complexes. For the base pair-drug fragment complexes, the order of interaction energy was found according to IAT4 $>$ BtAT3 $>$ BfAT4 and IGC3 $>\mathrm{BtGC} 2>\mathrm{BfGC} 2$, for AT and GC base pairs,
\end{abstract}

Interaction energy: This is the contribution to the total energy that is caused by an interaction between the objects being considered. $\pi-\pi$ stacking: This parameter refers to attractive, noncovalent interactions between aromatic rings, since they contain $\pi$-bonds, namely the face-centered stacked arrangement.

Electronic supplementary material The online version of this article (https://doi.org/10.1007/s13765-018-0348-6) contains supplementary material, which is available to authorized users.

Hossein Azizi Toupkanloo

h.azizi@neyshabur.ac.ir

1 Department of Physics and Chemistry, Faculty of Science, University of Neyshabur, P. O. Box 9319774400, Neyshabur, Iran

2 Computational Quantum Chemistry Laboratory, Department of Chemistry, University of Sistan and Baluchestan, P.O. Box 98135-674, Zahedan, Iran respectively. Furthermore, our results show that stacking interaction leads to an increase and decrease in hydrogen bond length that involved in the nucleic base-drug fragment interactions. DFT-calculated interaction energies for all present conformers were found to be in a good agreement with the bond critical points data from AIM analysis. In contrast, no reasonable linear correlation was observed between NBO analysis and stability of the all studied conformers. Finally, in order to verify the DFT and AIM results, docking calculations were performed using AutoDock software. According to the binding energy of drug-DNA from AutoDock calculations, the D2-Bt and D1-Bf are the most and the least stable structures, respectively.

Keywords AutoDock - Binding energy - Drug fragment · Interaction energy $\cdot \pi-\pi$ stacking

\section{Introduction}

Noncovalent interactions play a unique role in biological science, control diverse phenomena including boiling points of liquids, solvation energies and determine the structures of DNA, RNA, and proteins. The $\pi$-interactions including $\pi$-stacking, cation- $\pi$, anion- $\pi$, and $\mathrm{X}-\mathrm{H} \cdots \pi$ constitute one of the most important chemical classes of noncovalent interactions that contribute to biomolecular structure, drug binding, and the structure and properties of $\pi$-conjugated materials of interest in organic electronics and photonics [1-5]. Among the most prevalent noncovalent interactions, the preferred orientation of the aromatic groups may be related to the $\pi-\pi$ interactions [6]. To illustrate the importance of the issue, the aromatic-aromatic interactions play a crucial role not only in the 
stabilization of proteins, but also in the recognition processes of protein-protein and protein-ligand [7]. More than half a century, researcher has been interesting to the interactions between $\pi$-systems issue [8,9]. The results show that dispersion contributes significantly to the interaction energy (IE) is complemented by a varying degree of electrostatic interactions, where the electrostatic properties of these systems are a key determinant for their orientational preferences [10]. However, some important questions still remain regarding various classes of noncovalent interactions, such as how strong they are and how they are affected by introduction of substituents or modification with changing geometry. Therefore, in order to appropriate drug design, predict their physical properties or even choose one suitable for a specific application, it is necessary to make a link between the fundamental properties of the system such as electronic, molecular structure, as well as specific physical and chemical properties. By considering this, thorough understanding of noncovalent forces and their effects on biomolecular structure and function would aid the biotechnology and nanotechnology is possible [11]. The nucleic acids, one of the most important biological group including $\pi$-stacking interactions, have a key role in biological phenomena, because they interact reversibly with a broad range of chemical species that include water, metal ions and their complexes, small organic molecules, and proteins. Therefore, its interactions need to be studied in detail because of the importance of stacking between nucleic acid bases and others species in determining the structure and flexibility of DNA and RNA [12]. This interaction is very crucial in intercalation of drugs into DNA [13, 14]. Despite the presence of numerous published papers, there are still many questions about the characterization of interaction of drugs with nucleic acids. In this context, detailed knowledge of stacking interactions may be useful in the design of drugs intercalation within DNA [13]. Biologically, in some cases, hydrogen bond has an important role in the DNA and RNA bases. In order to this, Brovarets and coworkers [15] theoretically investigated the role of the intermolecular $\mathrm{CH} \cdots \mathrm{O} / \mathrm{N}$ hydrogen bonds in pairs of the DNA and RNA modified bases. They established $34 \mathrm{CH} \cdots \mathrm{O}$ and $7 \mathrm{CH} \cdots \mathrm{N}$ interactions that were detected by quantum chemical calculations in the 39 biologically important pairs involving modified nucleobases. Stacking interactions are also important for understanding of DNA sequence-dependent polymorphism, which is mainly determined by the properties of individual base pairs [16]. The $\pi$-stacking interactions are fundamental for various phenomena such as vertical base-base interactions stabilizing the double helical structure of DNA, intercalations of drugs with DNA, the packing of aromatic molecules in crystals, the formation of the 3D nucleic acid architectures, and the tertiary structures of proteins
[17-21]. So, detailed suitable information of the physical factors governing this interaction will give deeper insight into the structural and functional implications of aromatic interactions in biomolecules, particularly the nucleic acids, and to the design of new intercalating drugs with potential therapeutic value. Due to their importance, there numerous studies have been performed on the stacking interactions, both experimental [22, 23] and theoretical [24, 25]. The computational studies range from analyzing canonical base stacking [26] to unusual base stacking [27]. Among natural products which are biologically active, indoles are the most plentiful heterocycles, pharmaceuticals, agrochemicals and also are pertinent substructures in functional materials (Fig. 1). Also, the side chain of tryptophan amino acid is normally modeled with indole. Indole is composed of a benzene ring and pyrrole ring sharing one double bond. Hence, indole is an important heterocyclic system since it is often considered as a model for the chromophore of the tryptophan residue in proteins and it is the basis of drugs such as indomethacin and eletriptan [28, 29]. Other biologically active natural products are benzofuran and benzothiophene heterocyclic compounds in which a benzene ring is fused to that of a furan and thiophene molecules, respectively (Fig. 1). Benzofuran derivatives depict some potent biological properties such as antihyperglycemic, analgesic, antiparasitic, antimicrobial, antitumor, and kinase inhibitor activities [30]. The benzothiophene ring system and its derivatives are present in several drug candidates, which exhibit some interesting biological properties, for example, as antitumor [31] and antimicrobial [32]. For instance, Badichi Akher and coworkers [33] characterized the $\pi$-stacking interactions between aromatic amino acids and quercetagetin, which is one of the most representative flavonol compounds with biological and chemical activities. Their results show that the sum of donor-acceptor interaction energy between amino acids/ quercetagetin and the sum of electron densities $\rho$ calculated at bond critical points (BCPs) between them can be useful descriptors for prediction of the interaction energy values of the complexes. Heteroaromatic rings are key components in the most known drug molecules, and they play a crucial role in molecular recognition by proteins [5]. Their unique electronic structure with a distinct $\pi$-cloud located parallel above and below the ring plane allows for a variety of interaction patterns [34]. Interaction patterns exhibited by aromatic heterocycles comprise hydrophobic, polar, hydrogen bonding (H-bonding), cation- $\pi$ [35], amid- $\pi$ [36], halogen- $\pi$ [37], and $\pi$ stacking interactions [38]. These heterocyclic compounds demonstrate diverse pharmacological properties, and flexibility in their structure means a high degree of differentiation that has been proven to be useful for the search of novel therapeutic agents. These bicyclic fragments are 
<smiles>c1ccc2[nH]ccc2c1</smiles>

Indole (I)

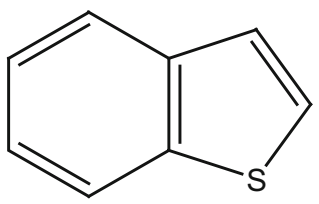

Benzothiophene (Bt)<smiles>c1ccc2occc2c1</smiles>

Benzofuran (Bf)<smiles>Nc1ncnc2[nH]cnc12</smiles>

Adenine (A)

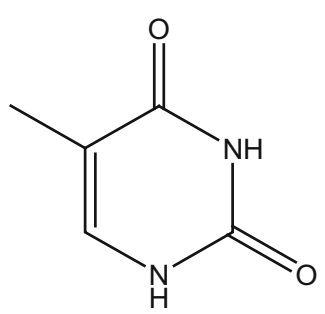

Thymine (T)

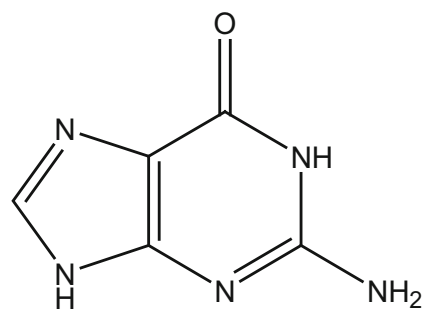

Guanine (G)<smiles>Nc1cc[nH]c(=O)n1</smiles>

Cytosine (C)

Fig. 1 Structures of studied molecules

found in many drugs, and it is possible they have genotoxic effects [39]. The aim of the present work is to focus on the $\pi-\pi$ stacking interactions between some popular drug fragments (DF) including indole (I), benzofuran (Bf), benzothiophene (Bt), and natural nucleo bases (see Fig. 1) using quantum mechanical method. Several conformations were considered for each base...DF complex with respect to different molecular interactions between two units. These molecular interactions and conformational changes influence the general behavior of the compounds. Thus, the conformations and interactions provide valuable information about the favorable properties which are useful todesign a drug with higher efficacy for a desired application. Manifestation of these interactions is discussed in detail. This study can help designing new and more effective drugs on interaction with DNA.

\section{Computational methods}

Geometry optimization and vibrational frequency calculations of molecules and complexes were performed using Gaussian 09 program package at the M062X/6$311++\mathrm{G}(\mathrm{d}, \mathrm{p})$ level of theory [40]. The CG and AT are labeled as Cytosine...Guanine and Adenine...Thymine base pairs, respectively. All calculated IEs $\left(\mathrm{kcal} \mathrm{mol}^{-1}\right)$ were performed in the gas phase. Binding energies (IEs or $\Delta E$ ) of the complexes have been corrected for the basis set superposition error using counterpoise method given by Boys and Bernardi [41]. The $\Delta E$ between the DF and the DNA bases was calculated according to the following equation:
$\Delta E=\left(E_{\text {Complex }}\right)-\left(E_{\mathrm{DF}}+E_{\mathrm{B}}\right)$,

where $E_{\mathrm{DF}}$ and $E_{\mathrm{B}}$ are the energies of the drug fragments and DNA base, respectively. $E_{\text {Complex }}$ is the energy of formed complexes between DF and DNA bases. Need to explain that DF are drug fragments including indole (I), benzothiophene $(\mathrm{Bt})$ benzofuran $(\mathrm{Bf})$ and $\mathrm{B}$ are guanine $(\mathrm{G})$, adenine (A), A-thymine (AT), G-cytosine (GC) base pairs.

We have employed the M06-2X functional of Truhlar and coworkers [42] which provides remarkably accurate predictions for a wide range of chemical systems, including nonbonded interactions [43]. For general use, the M06-2X functional exhibits good results not only for noncovalent complexes, but also for other ground- and excited-state properties [44]. The natural bond orbital (NBO) analysis was performed by the NBO 5.0 program package [45]. The topological properties of electron charge density were calculated by the atoms in molecules (AIM) method [46] using the AIM2000 program package [47] at the M062X/6$311++G(d, p)$ level of theory. Some of the important analysis parameters such as BCP, ChelpG, and $E^{2}$ is required to explain more. A point on inter-atomic surface where the gradient of electron density is equal to zero $[\nabla \rho(\mathbf{r})=0]$ is defined as BCP. In the CHELPG (= CHarges from ELectrostatic Potentials using a Gridbased method) scheme by Breneman and Wiberg [48], atomic charges are fitted to reproduce the molecular electrostatic potential at a number of points around the molecule. Finally, $E^{2}$ is defined as energy value required for charge transfer from donor orbital to acceptor orbital in NBO analysis or defined as second-order interaction energy between donor and acceptor orbitals. 


\section{Results and discussion}

\section{Guanine complexes}

In order to study the interaction between guanine base and medical fragments, different conformers of $\mathrm{Bt} \cdots \mathrm{G}(\mathrm{BtG})$, and $\mathrm{Bf} \cdots \mathrm{G}(\mathrm{BfG}), \mathrm{I} \cdots \mathrm{G}(\mathrm{IG})$ complexes were optimized at the $\mathrm{M} 062 \mathrm{X} / 6311++\mathrm{G}(\mathrm{d}, \mathrm{p})$ theoretical level. Moreover,
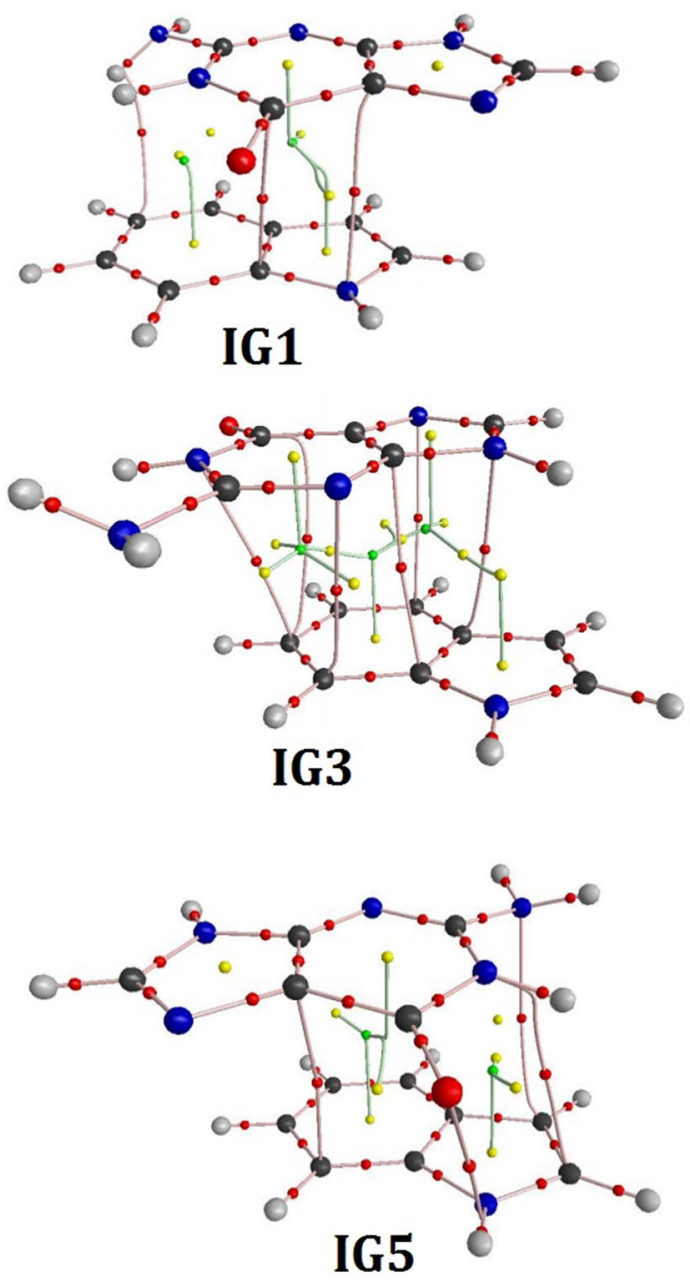

AIM and NBO analyses were also performed on the optimized complexes at the mentioned level.

\section{Indole-guanine (IG) complexes}

Based upon distribution of IEs, seven conformers were designated (IGx; $x=1-7$; see Fig. 2) which can be categorized into three groups according to the energy ranges.
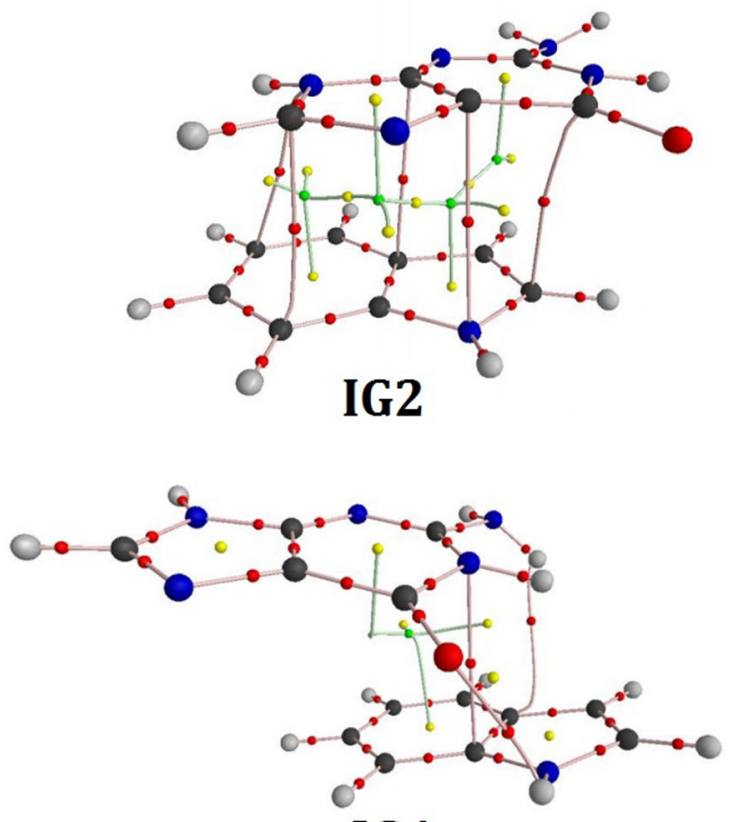

IG4

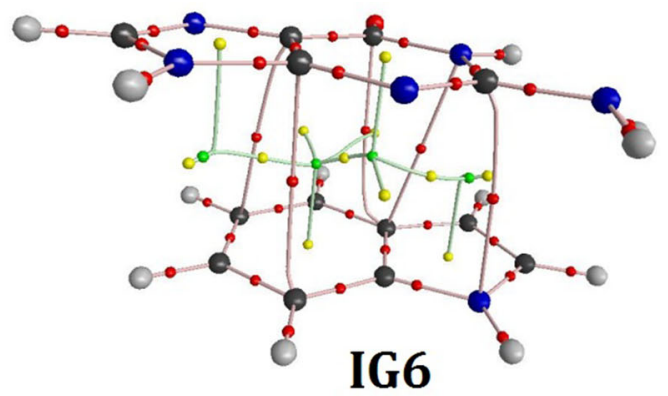

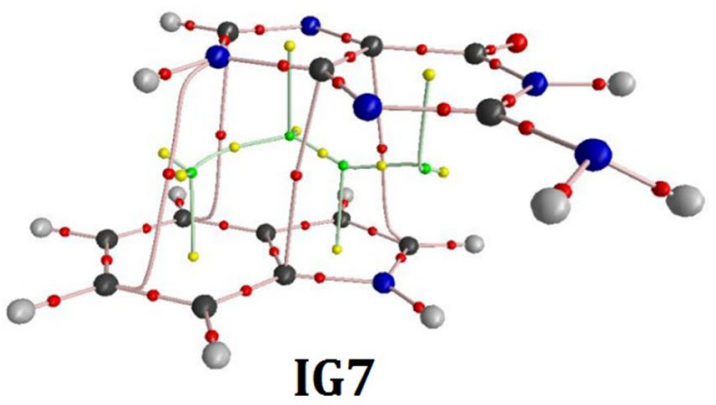

Fig. 2 Conformers designated for IGx complexes 
The first category included IG1 and IG4 conformers. Complex IG1 is the most stable conformer among the seven conformers. According to AIM analysis, the stability can be attributed to three BCPs between atoms in this conformation: (a) between the carbon of carbonyl in guanine base and one of the carbons of the indole cycle $\mathrm{O}=\mathrm{C} \cdots \mathrm{C}$, (b) between one of the carbons of guanine base and intercycle nitrogen of indole $\mathrm{HN} \cdots \mathrm{C}$, and (c) between one of the hydrogens of $\mathrm{NH}_{2}$ group of guanine and the carbon of indole. In the IG4 complex, a BCP is observed between the oxygen atom in the carbonyl group of guanine and the hydrogen atom in the $\mathrm{NH}$ group of indole $\mathrm{C}=\mathrm{O} \cdots \mathrm{HN}$; high distance between the $\mathrm{O}$ and $\mathrm{H}$ atoms $(2.235 \AA)$ and unsuitable direction make it so week that its stability becomes lower than IG1 (Fig. 2). The calculated $\Sigma \rho_{\mathrm{BCP}}$ values for the intermolecular BCPs of the IG1 and IG4 complexes are in agreement with the stability of these complexes, $\Sigma \rho_{\mathrm{BCP}}$ (IG1) $>\Sigma \rho_{\mathrm{BCP}}$ (IG4). Relative orientation of two units is more appropriate for $\pi-\pi$ stacking in conformation IG1, so due to stronger $\pi-\pi$ stacking interaction, it is more stable than the structure of IG4; guanine bends on the surface of indole molecule and decreases the $\pi-\pi$ stacking interaction between aromatic rings. According to the IEs, the IG2 and IG5 conformations have the second order. In both structures, no BCP was observed between $\mathrm{C}=\mathrm{O} \cdots \mathrm{HN}$ and $\mathrm{HNH} \cdots \mathrm{C}$ pairs, so those are less stable in comparison with these of the first group. Due to the $\mathrm{O}=\mathrm{C} \cdots \mathrm{C}$ and $\mathrm{NC} \cdots \mathrm{NH}$ interactions, the IG4 conformer is more stable than IG5. In the conformer IG5, the oxygen atom of guanine interacts with the nitrogen atom of indole $\mathrm{C}=\mathrm{O} \cdots \mathrm{NH}$; so, this conformation is less stable due to the repulsion between the lone pairs of oxygen and nitrogen. In the IG5 conformer, guanine bends on the indole ring and the distance between the oxygen atom of carbonyl group and the hydrogen atom of indole decreases to $2.423 \AA$. Thus, there is a weak interaction between oxygen and hydrogen which does not exist in IG2; it makes the sum of $\rho_{\mathrm{BCP}}$ in IG5 higher than that of IG2, which is not compatible with the stabilization energy of these two conformers. According to the IE ranges, the IG3, IG6, and IG7 conformers are in the third position. Due to that no BCP between $\mathrm{C}=\mathrm{O} \cdots \mathrm{HN}$ and $\mathrm{HNH} \cdots \mathrm{C}$ pairs was observed in all these three structures; therefore, concluded these conformers are less stable than the first group. From one point of view, in the structures of IG6 and IG3, a BCP between NC $\cdots$ NH pair makes IG6 and IG3 more stable than IG7. From another point of view, in the structure of IG6, there is a BCP between NC...NH pair in IG6 which was not observed in IG3 conformer, which makes IG6 more stable than IG3. None of these interactions were detected in the IG7 conformer, so it is the less stable conformer. In addition, the $\Sigma \rho_{\mathrm{BCP}}$ value is higher for IG6 conformer in comparison with two other conformers which are in excellent agreement with the calculated IEs. The $\rho$ values calculated in the intermolecular BCPs of effective interactions in the stability of various conformers of indoleguanine complex are reported in Table 1.

\section{Benzothiophene-guanine (BtG) complexes}

According to the IE range of $\mathrm{BtG}$ complexes, eight conformers (BtGx; $x=1-8$; see Fig. 3 ) can be classified in three groups. The BtG5 and BtG6 conformers are in the first category. Due to the formation of $\mathrm{H} \mathrm{NH} \cdots \mathrm{S}$ H-bond with a high $\rho$ value at the BCP, BtG6 is the most stable structure. The $\mathrm{O}=\mathrm{C} \cdots \mathrm{C}$ interaction, which is confirmed by a $\mathrm{BCP}$ in AIM analysis, is contributive to the stability of them in both structures. BtG1, BtG2, and BtG8 conformers make the second group. In the $\mathrm{BtG} 1$ and $\mathrm{BtG} 2$ conformers, the repulsion between lone pair electrons of nitrogen and sulfur, which is confirmed by a BCP value, decreases the stability of this conformer, but in the BtG8 conformer, the NC...S interaction is weaker due to the lower electron density on the carbon connected to the nitrogen, with a lower tendency interaction with lone pair electrons of sulfur. The BtG3, $\mathrm{BtG} 4$, and BtG7 conformers were established the third group. Due to the $\mathrm{O}=\mathrm{C} \cdots \mathrm{C}$ interaction, which is confirmed by the AIM analysis, BtG4 is more stable than other two complexes. The $\rho$ values calculated at the BCPs of the

Table 1 Stabilization energy (in $\mathrm{kcal} \mathrm{mol}^{-1}$ ) and the $\rho$ values (in au) calculated in the BCPs of the effective interactions in the stability of indole-guanine complexes

\begin{tabular}{|c|c|c|c|c|c|c|c|c|}
\hline & $\Delta E\left(\mathrm{kcal} \mathrm{mol}^{-1}\right)$ & {$[\mathrm{C}=\mathrm{O} \cdots \mathrm{HN}]$} & {$[\mathrm{C}=\mathrm{O} \cdots \mathrm{N}]$} & {$[\mathrm{O}=\mathrm{C} \cdots \mathrm{C}]$} & {$[\mathrm{NC} \cdots \mathrm{NH}]$} & {$[\mathrm{HNH} \cdots \mathrm{C}]$} & {$\left[\mathrm{H}_{2} \mathrm{~N} \cdots \mathrm{C}\right]$} & $\Sigma \rho \square 10^{2}$ \\
\hline IG1 & -15.769 & & & 9.5403 & 8.9996 & 7.1414 & & 2.5681 \\
\hline IG2 & -13.704 & & & 8.2989 & 8.4198 & & & 1.6719 \\
\hline IG3 & -10.411 & & & 6.4028 & & & & 0.6403 \\
\hline IG4 & -15.693 & 15.3706 & & & & 7.7368 & & 2.3107 \\
\hline IG5 & -13.414 & & 11.7681 & & & & 5.62 & 1.7388 \\
\hline IG6 & -10.418 & & & 7.4609 & 7.2393 & & & 1.4700 \\
\hline IG7 & -10.187 & & & & & & & 0.0000 \\
\hline
\end{tabular}



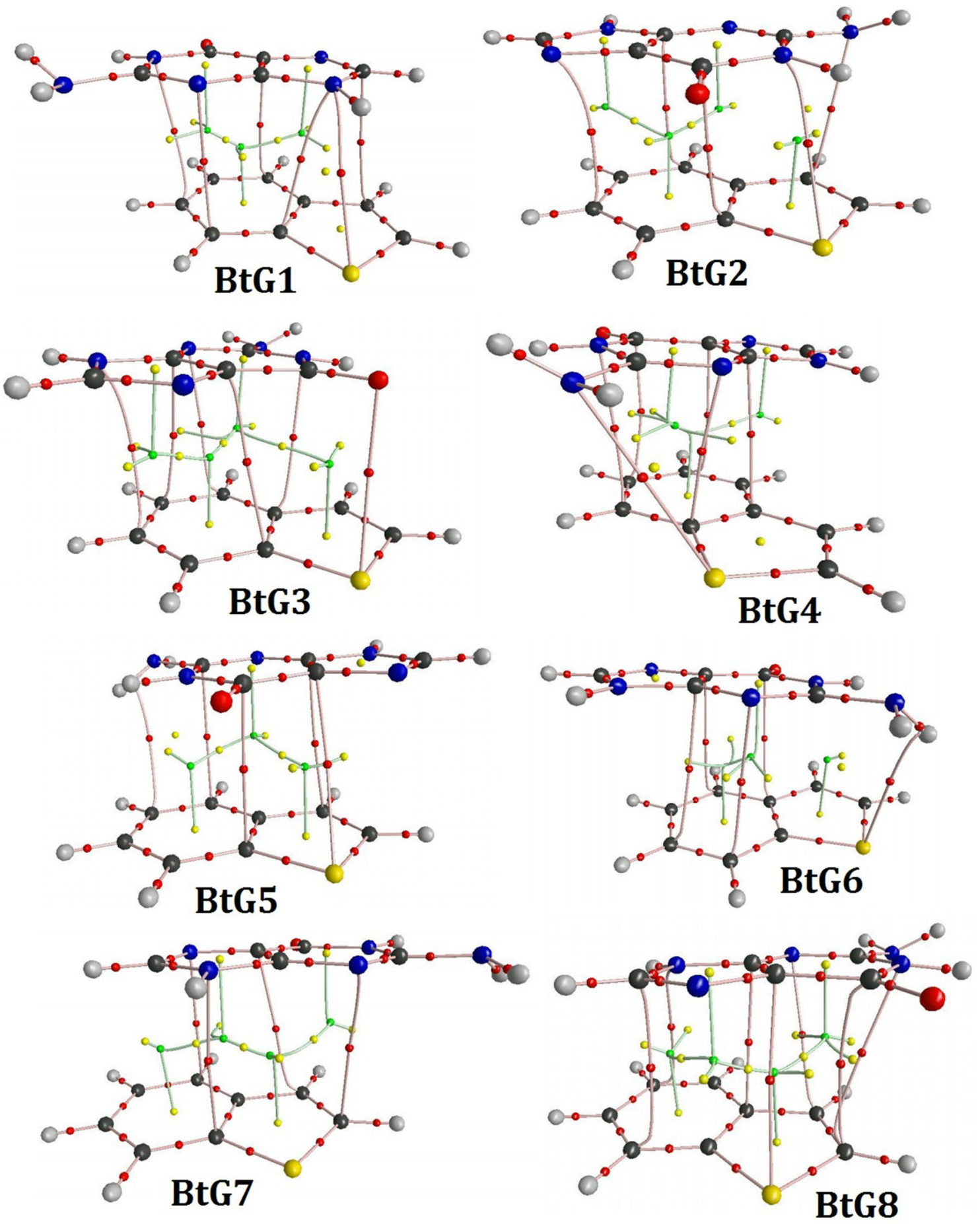

Fig. 3 Conformers designated for BtGx complexes

effective interactions in the stability of BtG complexes are reported in Table 2 .

\section{Benzofuran-guanine (BfG) complexes}

Corresponding to IE range of BfG, eight conformers (BfGx; $x=1-8$; see Fig. 4) can be categorized into three groups.
Among the BfG1, BfG3, and BfG7 conformers, from the first category, BfG1 conformer is the most stable conformer. Due to the $\rho$ value at the BCP of $\mathrm{O}=\mathrm{C} \cdots \mathrm{C}$ interaction, BfG1 and BfG3 conformers are more stable than BfG7 conformer. In addition, the $\mathrm{N}$... O interaction, which is confirmed by the AIM analysis, decreases the stability of BfG7 conformer. Orientation of units in BfG1 conformer is 
Table 2 Stabilization energy $\Delta E$ (in $\mathrm{kcal} \mathrm{mol}^{-1}$ ) and the $\rho$ values (in au) calculated at the BCPs of the effective interactions in the stability of benzothiophene-guanine complexes

\begin{tabular}{|c|c|c|c|c|c|c|c|c|c|}
\hline & $\Delta E\left(\mathrm{kcal} \mathrm{mol}^{-1}\right)$ & {$[\mathrm{HNH} \cdots \mathrm{S}]$} & {$[\mathrm{O}=\mathrm{C} \cdots \mathrm{C}]$} & {$[\mathrm{NC} \cdots \mathrm{S}]$} & {$[\mathrm{C}=\mathrm{O} \cdots \mathrm{S}]$} & {$\left[\mathrm{H}_{2} \mathrm{~N} \cdots \mathrm{C}\right]$} & {$[\mathrm{N} \cdots \mathrm{S}]$} & {$\left[\mathrm{H}_{2} \mathrm{~N} \cdots \mathrm{S}\right]$} & $\overline{\Sigma \rho \square 10^{2}}$ \\
\hline BtG1 & -11.168 & & & & & & 0.00681 & & 0.681 \\
\hline $\mathrm{BtG} 2$ & -11.046 & & 0.00783337 & & & 0.0062676 & 0.00711 & & 2.121 \\
\hline BtG3 & -8.951 & & & & 0.007408 & & & & 0.741 \\
\hline BtG4 & -10.003 & & 0.00590312 & & & & & 0.004802 & 1.071 \\
\hline BtG5 & -12.169 & & 0.00820479 & 0.007431 & & 0.0072458 & & & 2.288 \\
\hline BtG6 & -12.444 & 0.0083549 & 0.0081833 & & & & & & 1.654 \\
\hline BtG7 & -9.444 & & & & & & & & 0 \\
\hline BtG8 & -11.263 & & 0.00655607 & 0.007218 & & & & & 1.377 \\
\hline
\end{tabular}

better than BfG3; this makes stronger the $\mathrm{NH} \cdots \mathrm{O}$ H-bond and $\pi-\pi$ stacking interaction in BfG1, such that the conformer BfG1 becomes more stable than BfG3 conformer. The BfG2 and BfG5 conformers formed the second group. Although the stability of BfG2 conformer is lower than the conformers of first group, the calculated $\Sigma \rho$ value at the $\mathrm{BCPs}$ of $\mathrm{BfG} 2$ is higher than those of other conformers. The third group includes the BfG4, BfG6, and BfG8 conformers. The $\mathrm{O}=\mathrm{C} \cdots \mathrm{C}$ and $\mathrm{H}_{2} \mathrm{~N} \cdots \mathrm{C}$ interactions, confirmed by the AIM analysis, make BfG4 more stable than BfG6 and BfG8. It is expected that the C...O interaction makes BfG8 conformer more stable than BfG6. The $\Sigma \rho$ values are in good agreement with the stabilization energy for these conformers. The $\Sigma \rho$ value calculated at the BCPs of the effective interactions in the BfG complexes is given in Table 3.

\section{Comparison between groups}

Among the most stable conformers of three categories, IG1 is the most stable conformer including $\Delta E=-15.769 \mathrm{kcal} \mathrm{mol}^{-1}$ (Table 4). This stability is due to the presence of $\mathrm{O}=\mathrm{C} \cdots \mathrm{C}, \mathrm{NC} \cdots \mathrm{NH}$, and $\mathrm{HNH} \cdots \mathrm{C}$ interactions. The BtG6 conformer with $\Delta E$ equal to $-12.44 \mathrm{kcal} \mathrm{mol}^{-1}$ is second rank in the energy ranking. The calculated $\Sigma \rho$ value at the intermolecular BCPs of IG1, BtG6, and BfG1 conformers are equal to 0.025681, 0.0165382 , and 0.0152308 , respectively. The maximum and minimum values correspond to the most and least stable conformers, respectively. The trend of the different bonds length corresponds to the complex IE shows that in $\mathrm{I} \cdots \mathrm{G}$ complex, changes in the lengths of bonds constructing the effective indole and guanine cycles in $\pi-\pi$ stacking interactions for different conformers can impact abovementioned interactions. It is also observed that changes in the length of carbon-nitrogen bond (C8-N13) have a linear relationship with IE of $\mathrm{I} \cdots \mathrm{G}$ and the decrease in bond length leads to formation of most stable conformer. In contrast, changes in $\mathrm{C} 2-\mathrm{N} 13$ bond length have no reasonable relationship with IE. Moreover, there is a linear relationship between the changes of C27-N22 bond length and complex IE I $\cdots \mathrm{G}$ as the bond length was decreases leads to formation of most stable conformer. In addition, there is a linear relationship between nitrogen-hydrogen bond length (N13-H14) and $\mathrm{I} \cdots \mathrm{G}$ complex IE, as the increase in bond length leads to formation of most stable conformer and an H-bond with guanine. Furthermore, as the conformers become stable, C27-O28 bond length increases in a way that the coexisting stability of $\mathrm{N}-\mathrm{H}$ and $\mathrm{C}-\mathrm{O}$ bonds confirms the formation of $\mathrm{H}$-bond in all the complexes. In BtG and BfG complexes, there is no reasonable relationship between the change in bond length and complex stabilization energy.

\section{Indole-adenine (IA) complexes}

In order to investigate the interaction between adenine base and medical pieces, various conformers of complexes indole-A (IA), benzothiophene-A (BtA), and benzofuranA (BfA) were optimized at M062X/6311++G(d,p) level. Moreover, according to the AIM and NBO analyses, the atomic charges were calculated by the ChelpG method (Fig. 5). Among the seven possible conformers of IA complexes that are labeled IAx ( $x=1-7$; see Fig. 5), IA6 is the most stable conformer. This stability can be attributed to strong $\pi-\pi$ stacking interaction that is specified by many BCPs between carbon atoms of adenine base and indole. In addition, ChelpG charges show that in all conformers, the charge transfer occurs from indole to adenine and the highest charge transfer corresponds to the most stable IA5 and IA6 conformers. In contrast, about the IA3 and IA4 conformers with the least stable, the minimum amount of charge transfers between units. In the $\mathrm{N} \cdots \mathrm{N}$ interaction (the nitrogen atoms of adenine) and indole which is specified via a BCP makes between these atoms, IA 3 is the least stable in comparison with other conformers of these group. A reasonable relationship was observed between the calculated ChelpG charges for indole and the $\Delta E$ values for this type of complexes. The calculated 

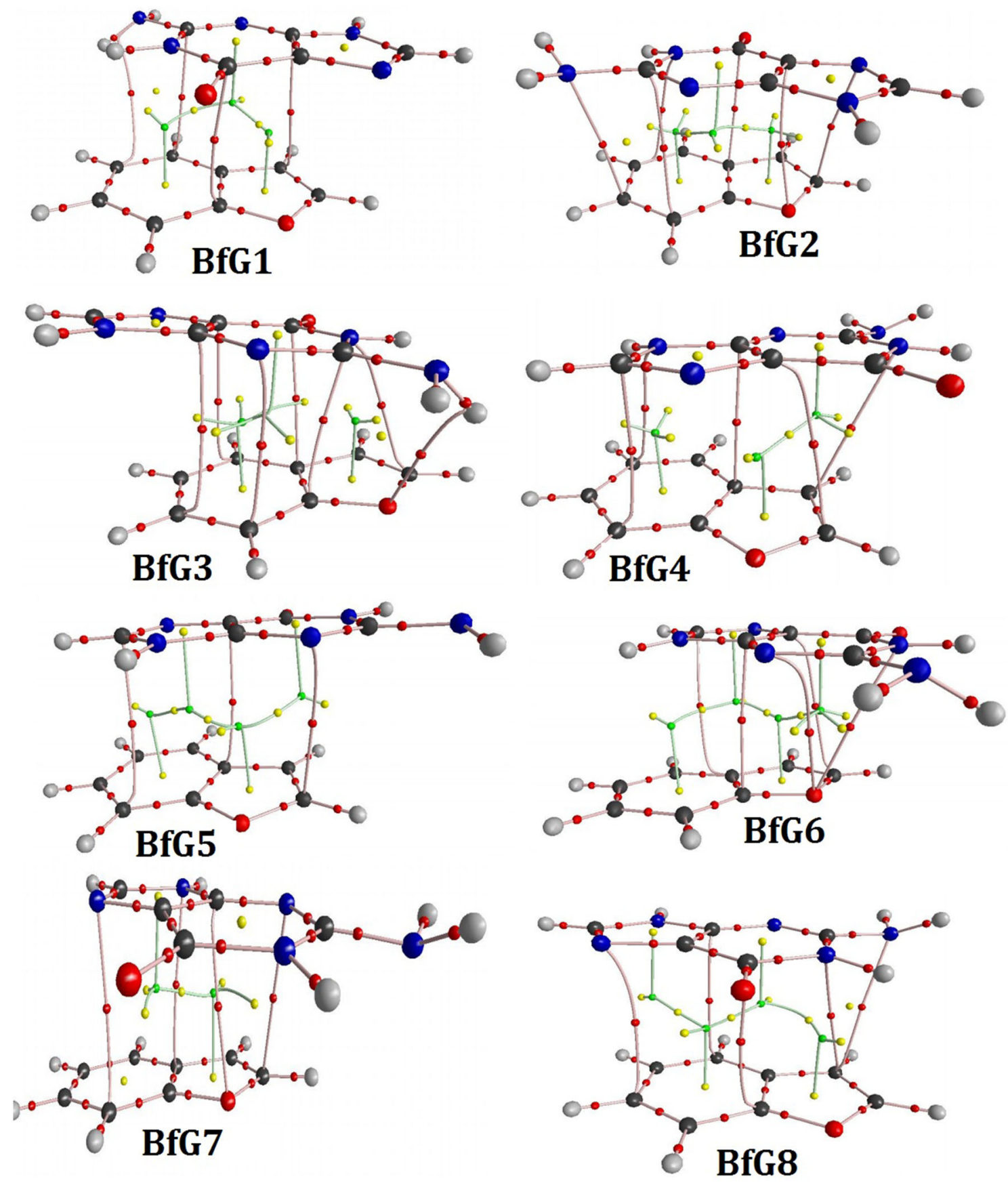

Fig. 4 Conformers designated for BfGx complexes

$\Delta E$ and $\Sigma \rho$ values in the BCPs of effective interactions in the stability of IA complexes are given in Table 5 .

\section{Benzothiophene-adenine (BtA) complexes}

Among the eight possible conformers of BtA complexes specified as BtAx ( $x=1-8$; see Fig. 6), BtA6 is the most stable conformer. The higher stability of this conformer can be attributed to the $\mathrm{C} \cdots \mathrm{C}$ interaction between carbon atoms of adenine base and benzothiophene, which is distinguished by an intermolecular BCP. BtA3 and BtA5 are the least stable conformers which have the least amount of calculated $\Sigma \rho$ at BCPs. The ChelpG charge data reveal that charge transfer is done from benzothiophene to adenine in all conformers with the exception of $\mathrm{BtA} 3$ and BtA4 (Fig. 6). The calculated ChelpG charges and the $\rho$ values at the most important BCPs, and the $\Sigma \rho$ values of effective 
Table 3 Stabilization energy $\Delta E$ (in $\mathrm{kcal} \mathrm{mol}^{-1}$ ) and the $\rho$ values (in au) calculated at the BCPs of the effective interactions in the stability of benzofuran-guanine complexes

\begin{tabular}{|c|c|c|c|c|c|c|c|c|}
\hline & $\Delta E\left(\mathrm{kcal} \mathrm{mol}^{-1}\right)$ & {$[\mathrm{C} \cdots \mathrm{O}]$} & {$[\mathrm{O}=\mathrm{C} \cdots \mathrm{C}]$} & {$[\mathrm{HNH} \cdots \mathrm{O}]$} & {$[\mathrm{N} \cdots \mathrm{O}]$} & {$[\mathrm{N} \cdots \mathrm{O}]$} & {$\left[\mathrm{H}_{2} \mathrm{~N} \cdots \mathrm{C}\right]$} & $\Sigma \rho \square 10^{2}$ \\
\hline BfG1 & -11.441 & & 0.00843972 & & & & 0.0067911 & 1.5231 \\
\hline BfG2 & -10.853 & 0.007324 & 0.00799144 & & & & 0.0065916 & 2.1907 \\
\hline BfG3 & -11.434 & & 0.00842655 & 0.00817935 & & & & 1.6606 \\
\hline BfG4 & -9.517 & & 0.00775370 & & & & 0.0064131 & 1.4167 \\
\hline BfG5 & -10.323 & & & & & & & 0 \\
\hline BfG6 & -8.478 & & & & & & & 0 \\
\hline BfG7 & -11.048 & & & & 0.0071234 & 0.00726 & & 1.4387 \\
\hline BfG8 & -8.543 & 0.008904 & & & & & & 0.8904 \\
\hline
\end{tabular}

Table 4 Relationship between bond length (in $\AA$ ) and IE in IGx complexes

\begin{tabular}{llllll}
\hline & $\Delta E\left(\mathrm{kcal} \mathrm{mol}^{-1}\right)$ & $r_{\mathrm{C} 8-\mathrm{N} 13}$ & $r_{\mathrm{C} 2-\mathrm{N} 13}$ & $r_{\mathrm{N} 13-\mathrm{H} 14}$ & $r_{\mathrm{C} 27-\mathrm{N} 22}$ \\
\hline IG1 & -15.769 & 1.3753 & 1.37446 & 1.00948 & 1.41806 \\
IG2 & -13.704 & 1.37612 & 1.3746 & 1.00837 & 1.42437 \\
IG3 & -10.411 & 1.3792 & 1.37617 & 1.00583 & 1.43008 \\
IG4 & -15.693 & 1.37362 & 1.37496 & 1.01242 & 1.41568 \\
IG5 & -13.414 & 1.37603 & 1.37514 & 1.01002 & 1.42044 \\
IG6 & -10.418 & 1.38025 & 1.37802 & 1.0058 & 1.42491 \\
IG7 & -10.187 & 1.3806 & 1.37443 & 1.00551 & 1.43149 \\
\hline
\end{tabular}

interactions in the stability of benzothiophene-adenine complexes are reported in Table 6.

\section{Benzofuran-adenine (BfA) complexes}

Among the seven possible conformers of BfA complexes that are labeled as BfAx ( $x=1-7$; see Fig. 7), BfA6 is the most stable conformer. The higher stability of this conformer can be attributed to the $\mathrm{C}$... $\mathrm{C}$ interaction between adenine base and benzofuran. BfA1 is the least stable conformer with the minimum $\Sigma \rho$ value at BCPs. The ChelpG charges show that charge transfer is done in all conformers, with the exception of BfA3 and BfA4 from benzofuran to adenine. The $\Delta E$ values, ChelpG charges, $\Sigma \rho$, and the $\rho$ values calculated at the most important BCPs of effective interactions between BfA complexes are given in Table 7 and Fig. 7. The change in the C4-C5 bond length of indole is in a linear relationship with IE of IAx. The results show that the stability of complexes increases by increasing bond length. Moreover, there is a linear relationship between the changes of N26-H31 bond length of adenine base and the IE value of IAx complexes. Higher bond lengths correspond to the more stable conformers. Moreover, the presence of interaction between indole $\mathrm{C} 4$ atom and adenine base N26 atom makes IA6 the most stable conformer. There is a linear relationship between
C2-C3 and C4-C5 bonds length changes in benzothiophene and the IE values of the BtAx complexes, such that the elongation in mentioned bond length was occurred, and the stability of complexes increases. Moreover, there is a linear relationship between changes in the N26-C2 and N25-H30 bond lengths of adenine base and the IE values of BtAx complex, such that the more stable complexes are accompanied by longer bond lengths. Furthermore, interaction between $\mathrm{C} 3$ of benzothiophene and $\mathrm{C} 20$ of adenine base makes BtA6 the most stable conformer. There is no reasonable relationship between the bond length changes and the IE in BfAx. However, there is a reasonable relationship between the $\mathrm{C} 16-\mathrm{C} 17$ bond length and IEs of complexes. The BfAx complexes become more stable by the increase in the bond length.

\section{The NBO analysis}

Donor-acceptor IEs $\left(E^{2}\right)$ were obtained from NBO analysis on the M062X/6311++G(d,p) level. In the guanine complexes, the most stable conformer is BtG6 with the most $\sum E^{2}(\mathrm{lpDF} \rightarrow \sigma * \mathrm{G}$ or $\mathrm{A})$, and the least stable conformer is $\mathrm{BtG} 3$ with the least $\sum E^{2}$, but in general, there is no reasonable correlation between the stabilization energy of complexes and $\sum E^{2}$ in the guanine complexes (Fig. S1). On the other hand, the $\sum E^{2}$ values decrease by the increase in the stability of conformers for the BtAx and BfAx complexes, where a logical linear correlation is observed between two parameters. However, there is no reasonable relationship between the $\sum E^{2}$ values and the stability of conformers for the IAx complexes (see Table S1).

\section{Interactions of medical fragments with the AT and GC base pairs}

In order to investigate the interaction of indole, benzothiophene, and benzofuran fragments with the AT and GC base pairs, all IAT, BtAT, BfAT, ICG, BtCG, and BfCG 


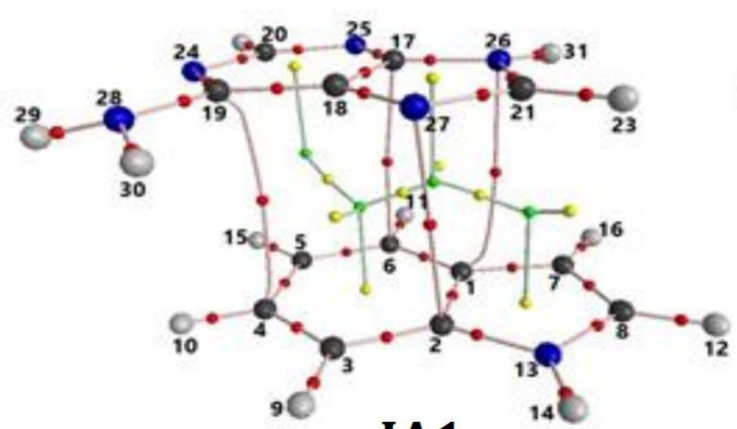

IA1

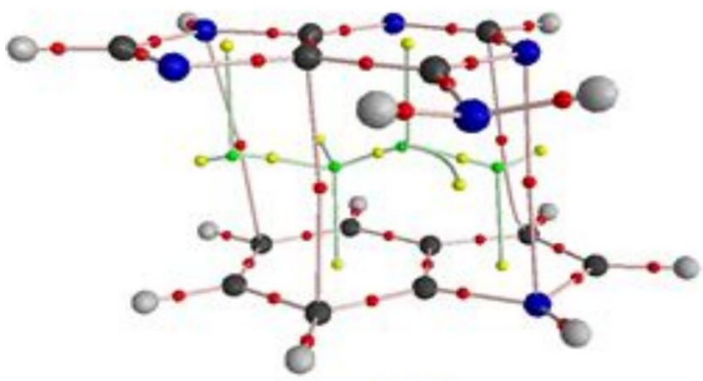

IA3

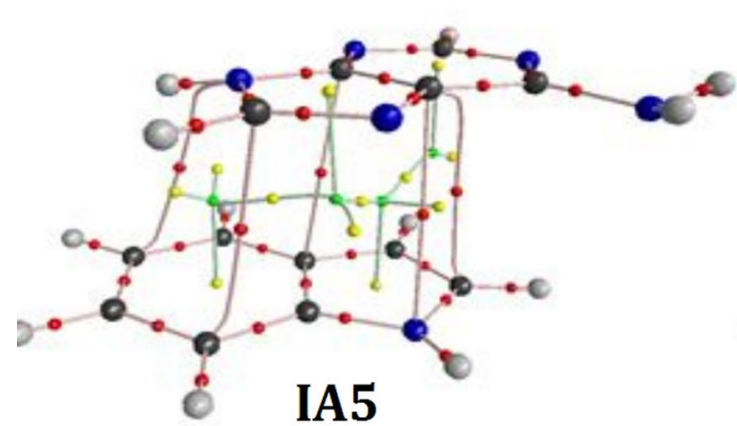

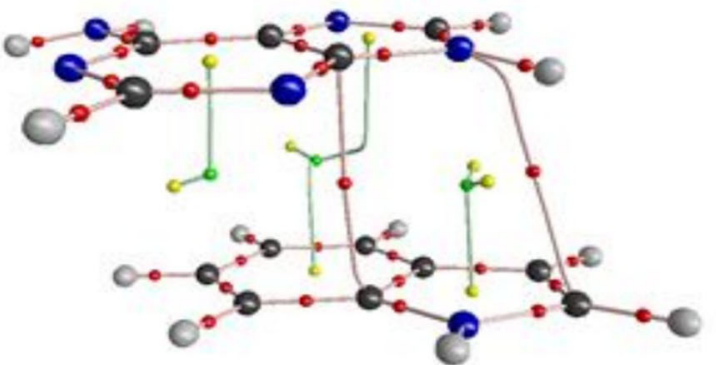

IA2

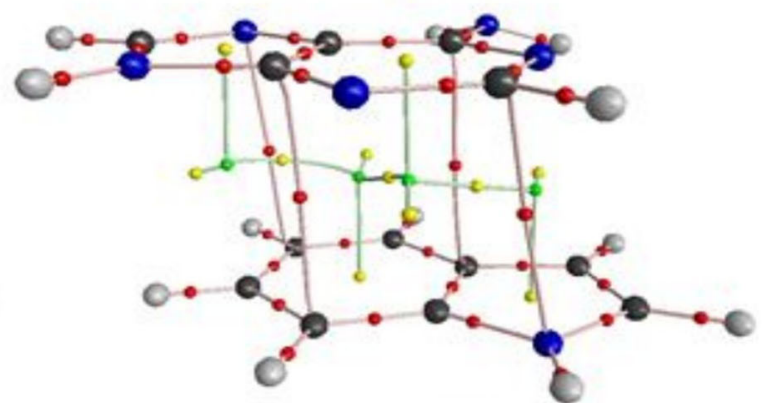

IA4

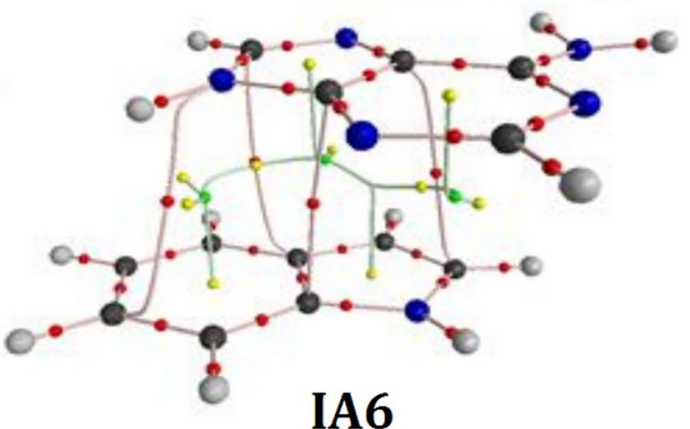

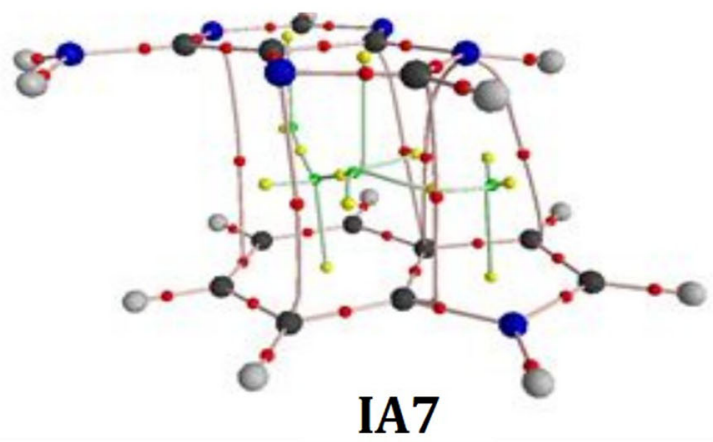

Fig. 5 Conformers designated for IAx complexes

complexes were optimized at the M062X/6-31G(d,p) computational level.

\section{The complexes of AT base pair}

In order to study the interaction of indole with AT, four different conformers named IATx $(x=1-4$; see Fig. S1) were evaluated by IE and characterization of bond critical intermolecular interactions. For IAT4, which is the most stable conformer, no reasonable relationship is observed between the calculated $\Sigma \rho$ values (or the $\rho_{\max }$ value) at the intermolecular interactions by the AIM analysis and the IE values, while both $\mathrm{H}$-bonds of the AT base pair become stronger (see Table S2). However, the $\Sigma \rho_{\mathrm{HB}}$ value of two 


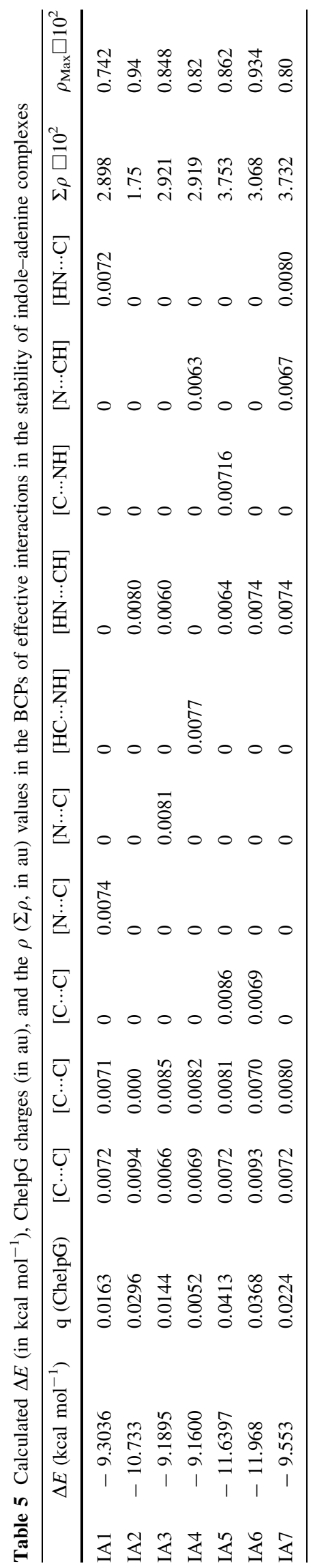

H-bonds of AT base pair is lower than that of other conformers $(x=1-3)$. With respect to the IAT4 conformer, the N8-H26 H-bond length of AT decreases in complexation, while other H-bond ( $\mathrm{H} 14 \cdots \mathrm{O} 27)$ becomes shorter in this process. Four conformers have been considered for the BtATx $(x=1-4$; see Fig. S2) complexes in which the BtAT4 is the most stable conformer. The calculated $\Sigma \rho$ values at the observed BCPs between the Bt and AT units are in agreement with the IE values (see Table S3). Similar trends were observed for both the IE and $\Sigma \rho$ values. This tendency is also in agreement with the $\mathrm{H} \cdots \mathrm{O}$ bond length and corresponding $\rho_{\mathrm{BCP}}$ values. Although the most stable conformer has the longest $\mathrm{N} \cdots \mathrm{H}$ bond length and the lowest $\rho_{\mathrm{HB} 1}, \rho_{\mathrm{HB} 2}$ (correspond to the H-bonds of the AT base pair), the trends of these data are not in agreement with the IE of conformers. If only the IE values were considered, we concluded that the BtAT3 is the most stable conformer (more negative), but this trend in contrast to the $\mathrm{H} \cdots \mathrm{O}$ and $\mathrm{N} \cdots \mathrm{H}$ bond length changes.

Four conformers were also considered for BfATx $(x=1-4$; see Fig. S3) complex based on the IE values; the BfAT4 is the most stable conformer (see Table S4). The calculated $\rho$ value at the BCPs of AT base pair increase on complexation process was the highest value corresponds to

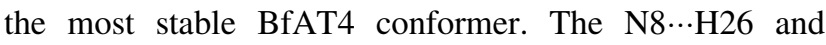

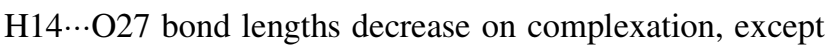

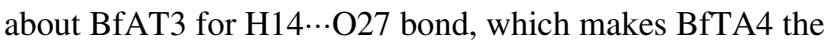
most stable conformer. With the exception of BfAT2, the trend in the IE values is in agreement with the $\Sigma \rho$ values calculated at the BCPs of intermolecular interactions.

\section{The interaction of I, Bt, and Bf with GC}

Herein, four different conformers of IGC complex, named as IGCx $(x=1-4$; see Fig. S4), were evaluated via IE estimation and base pairs H-bond investigation (see Table S5). The HN...CO bond, which is predicted by a $\mathrm{BCP}$ in the results of AIM, between nitrogen atom of indole and carbon atom of guanine with the highest $\rho_{\mathrm{BCP}}$ value among different conformers, makes IlGC3 the most stable conformer. On the other hand, the lowest $\Sigma \rho_{\mathrm{BCP}}$ value of three $\mathrm{H}$-bonds between $\mathrm{G}$ and $\mathrm{C}$ base corresponds to this conformer. The $\mathrm{H} 13 \cdots \mathrm{O} 20$ distance increases on complexation process with I, while the $\mathrm{N} 6 \cdots \mathrm{H} 22$ and $\mathrm{O} 9 \cdots \mathrm{H} 25$ distances decrease on complexation procedure. In general, it can be said that changes in the H-bond lengths have been in the similar direction of complex stability. Four conformers named $\operatorname{BtGCx}(x=1-4$; see Fig. 5) were observed for BtGC complex, in which BtGC2 has the most stable conformer. The BCP of $\mathrm{HC} \cdots \mathrm{CO}$ bond has the highest density value between carbon atoms of $\mathrm{Bt}$ and carbonyl group of $\mathrm{G}$ base. The lowest $\Sigma \rho_{\mathrm{HBCP}}$ value for three $\mathrm{H}$-bonds formed between base pairs corresponds 

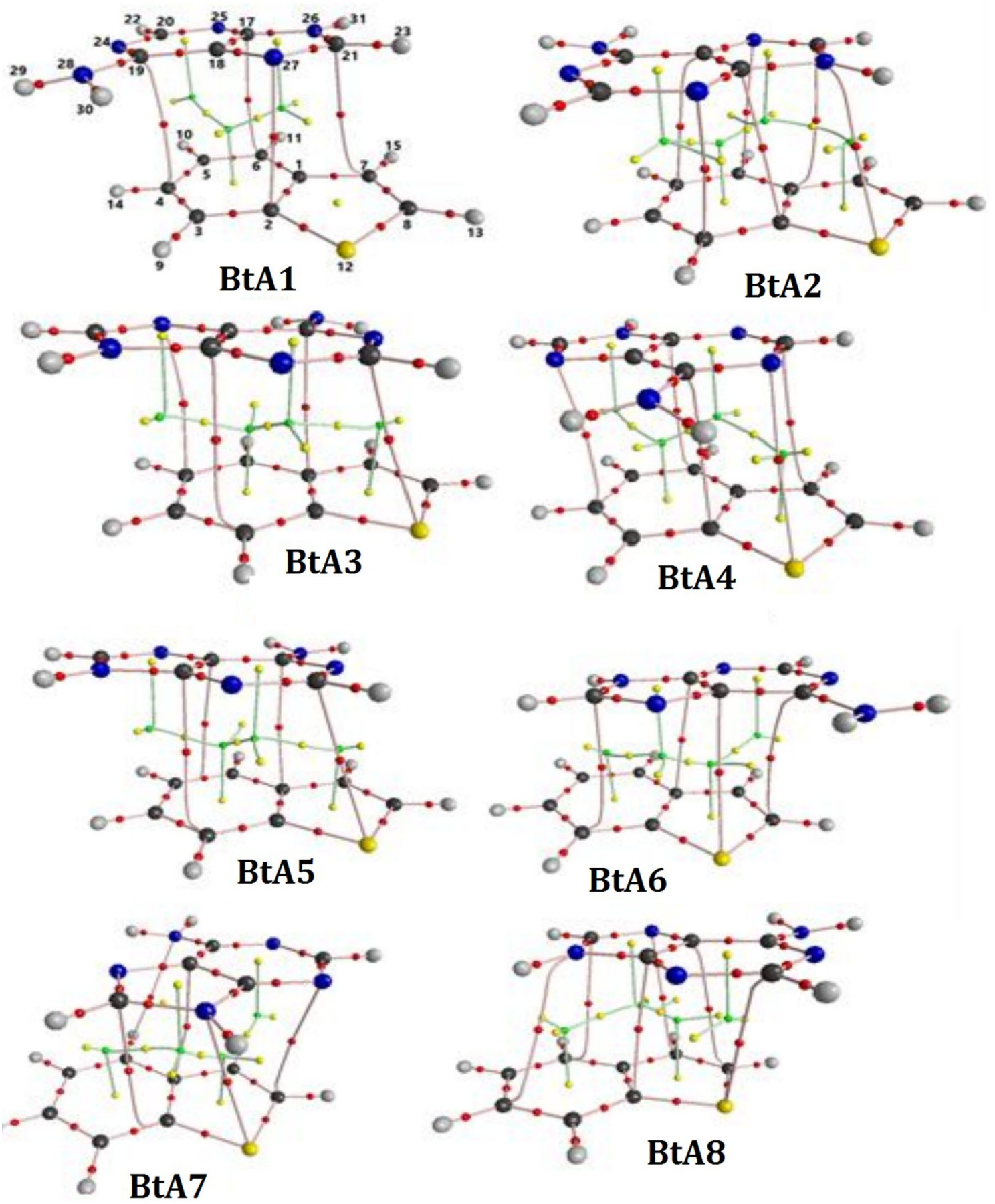

Fig. 6 Conformers designated for BtAx complexes

to this conformer (see Table S6). The $\mathrm{H} 13 \cdots \mathrm{O} 20$ and $\mathrm{O} 9 \cdots \mathrm{H} 25 \mathrm{H}$-bonds become weaker with respect to the increase in the length for this conformer, while the reverse

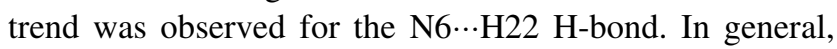
the stabilized conformers are in agreement with the changes in these bond lengths.
Four conformers BfGCx ( $x=1-4$; see Fig. S6) have been considered for the BfGC complex, in which BfGC2 is the most stable conformer. The lowest $\Sigma \rho_{\mathrm{HBCP}}$ and $\rho_{\mathrm{Max}}$ values were calculated between two units of this conformer (see Table S7). The length of all three H-bonds formed between $\mathrm{G}$ and $\mathrm{C}$ bases has been decreased in the BfGC2 
complex on complexation. The following equations were used in our calculations (see Tables S8 and S9):

$$
\begin{aligned}
& \Delta E_{\mathrm{HB}}=E(\text { base pair })-(E \text { base } 1+E \text { base } 2), \\
& \begin{aligned}
\Delta E_{\mathrm{HB}}+\Delta E_{\mathrm{S}} & =\Delta E_{\text {Complex }} \\
& =E_{\text {Complex }}-(E \text { base } 1+E \text { base } 2+E \text { drug }) .
\end{aligned}
\end{aligned}
$$

H-bond deformation energy (HBDE):

$\Delta \Delta E_{\mathrm{HB}}=\Delta E_{\mathrm{HB}}(2)-\Delta E_{\mathrm{HB}}(1)$

$\Delta E_{\mathrm{S}}(1)=E_{\text {Complex }}-(E$ base $1+E$ base $2+E$ drug $)$

Stacking deformation energy

(SDE):

$\Delta \Delta E_{\mathrm{S}}=\Delta E_{\mathrm{S}}(2)-\Delta E_{\mathrm{S}}(1)$

\section{Complexes of I, Bt, and Bf with AT base pair}

In all conformers of indole complex with AT base pair, the charge transfer is carried out from adenine and indole to thymine so that in the most stable conformer (IAT4), the highest and lowest charges were observed on thymine and indole, respectively. In addition, for the most stable conformer (IAT4), $\sum E^{2}$ has the lowest value. In the complex of Bt with AT base pair, for all conformers (except BtAT2), charge transfer occurs from adenine to $\mathrm{Bt}$ and thymine in a way that in the most stable conformer (BtAT3), the lowest charge was observed on the Bt surface. Furthermore, in the most stable conformer (BtAT3), $\sum E^{2}$ is lower than compared with BtAT1 and BtAT2 conformers, but in comparison with BtAT4 conformer it is higher. In the complex of $\mathrm{Bf}$ with AT base pair, for all conformers, charge transfer is performed from adenine to $\mathrm{Bf}$ and thymine in a way that in the most stable conformer (BfAT4), the lowest charge is seen on Bf, adenine, and thymine. Additionally, in the most stable conformer (BfAT4), $\sum E^{2}$ has the highest value (see Table S10).

\section{Complexes of I, Bt, and Bf with GC base pair}

In the complex of indole with GC base pair, for all conformers (except IGC1), charge transfer was observed from cytosine to guanine and indole in a way that in the most stable conformer (IGC3), the highest charge was detected on indole, adenine. Furthermore, in the most stable conformer (IGC3), $\sum E^{2}$ has the highest value. In the complex of Bt with GC base pair, for all conformers (except BtGC3 and BtGC4), charge transfer is done from cytosine to guanine and $\mathrm{Bt}$, but in the most stable conformer (BtGC2), no reasonable relationship was found between data. Also, in the most stable conformer (BtGC2), $\sum E^{2}$ is lower than $\mathrm{BtGC} 1$ and $\mathrm{BtGC} 3$, but it is higher than BtGC4. For the most stable complex structure (BfGC2) of $\mathrm{Bf}$ with $\mathrm{GC}$ base pair, charge transfer is done from cytosine to guanine 

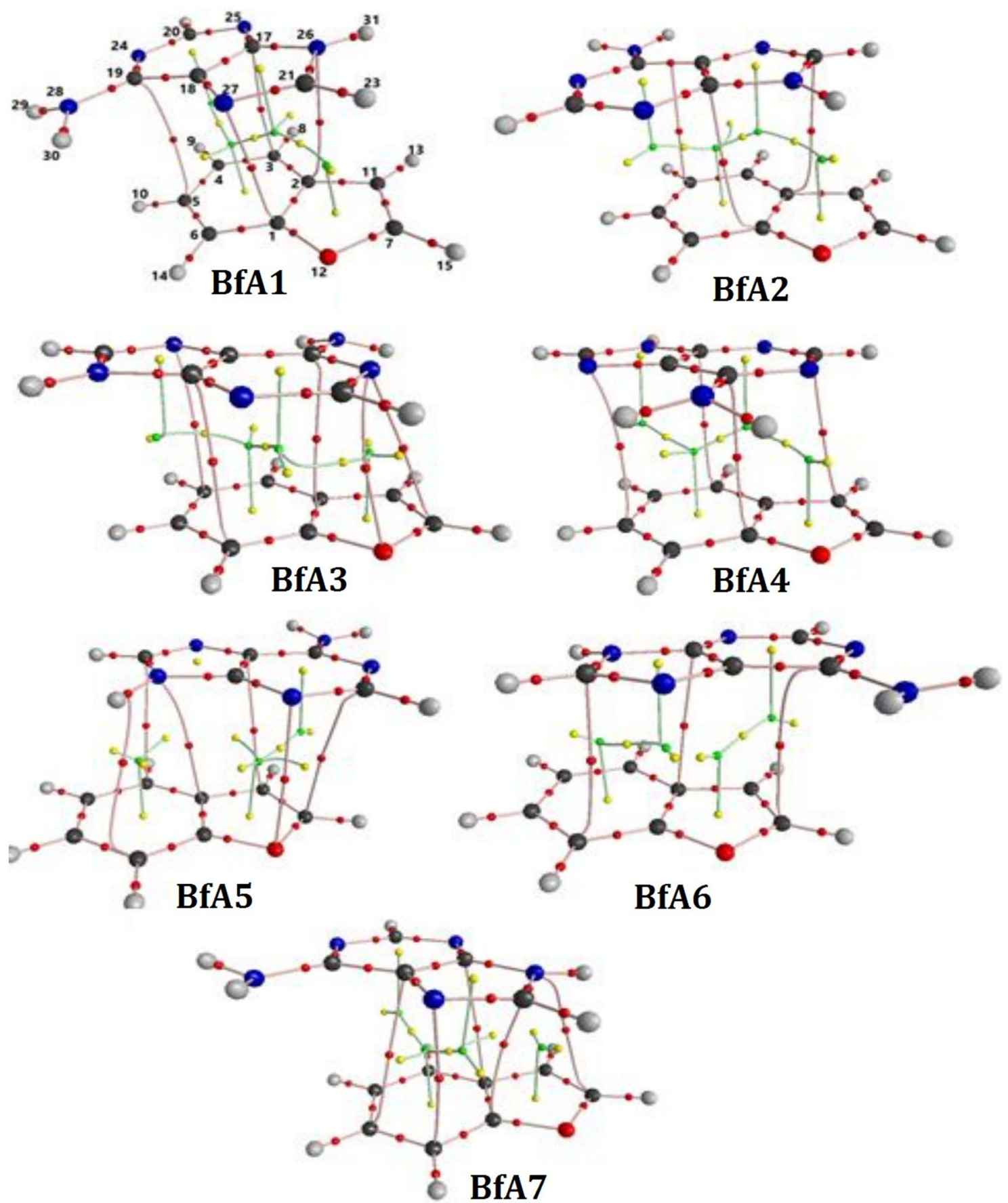

Fig. 7 Conformers designated for BfAx complexes

and $\mathrm{Bf}$ in a way that the highest and the lowest charges are seen on guanine and Bf, respectively. Moreover, in the most stable conformer (BfGC2), $\sum E^{2}$ is lower than BfGC3 and BfGC4, but it is higher than BfGC1 (see Table S11).
Comparing IATx, BtATx, BfATx with IGCx, BtGCx, BfGCx

The calculated $\rho_{\text {Max }}(\mathrm{BCP})$ values for the most stable conformer of the IGC complexes (IGC3) are higher than those for the most stable conformer of the IAT complexes 
(IAT4). Apart from these data, the $\Sigma \rho_{\text {Max }}$ (BCP) values are high for the most stable conformers of GC complexes.

\section{DNA docking calculations}

Although quantum mechanical calculations are time-consuming for large structures, new computational techniques and softwares allow us to calculate some physical and chemical factors for great structures. In this work, using AutoDock [49] software and three sequences of DNA extracted from Protein Data Bank (PDB site) [50], intercalation of three drug fragments (DF) into DNA structure was investigated and binding energies and inhibition constant (KI) were obtained (see Table 8). The main reason to use docking was to predict the intercalation of DF process in the DNA site and observe its three-dimensional structure. After preparation of DF and three sequences of DNA extracted from PDB site (D1, D2, D3), dimensions of bounding box were determined in a way that medical fragment and intercalation site are incorporated within the box. After that, calculations were performed in order to obtain the best orientations and binding energies. Among all existing complexes, corresponding to binding energy of drug with DNA, the D2-Bt and D1-Bf are the most and the least stable structures, respectively (see Tables 9, 10). In all DFs, the binding energies of CG/CG sequence with each fragment are greater than two other sequences of DNA (see Fig. 8). It should be noted that investigated DFs are part of medical structures that docking calculations have been performed already on them. Therefore, by comparing the calculations on whole drug and DFs, it can be concluded that these calculations have good adaptability with each other. It was observed that $\mathrm{Bt}$ fragment separated from raloxifene has the highest binding energy average with biological bases and the medical fragment of $\mathrm{Bf}$ separated from befunolol has the lowest average binding energy with biological bases.

As a final discussion, from the results of our study, the following main points were presented for emphasis and importance use of calculations in drug design:

1. In this study, using quantum mechanical calculations, a comprehensive understanding of the effects of charge on the more stable states of drug fragment-

Table 8 PDB codes of DNA sequences extracted from PDB site, interaction sites, and symbols used for sequences

\begin{tabular}{lll}
\hline PDB Code & Intercalation site & Symbol \\
\hline 1MTG & GA/TC & D1 \\
1N37 & CG/CG & D2 \\
1X95 & TG/CA & D3 \\
\hline
\end{tabular}


Table 9 Values of binding energies, inhibition constants, and bounding box size

\begin{tabular}{|c|c|c|c|c|}
\hline Complexes & Binding energy $\left(\mathrm{kcal} \mathrm{mol}^{-1}\right)$ & kI (micro-molar) & Size of bounding box & Interaction \\
\hline D1-I & -4.05 & 1070 & $52,56,22$ & Stacking, H-bonding \\
\hline $\mathrm{D} 1-\mathrm{Bt}$ & -3.91 & 1370 & $54,56,22$ & Stacking \\
\hline $\mathrm{D} 1-\mathrm{Bf}$ & -3.84 & 1540 & $52,54,24$ & Stacking \\
\hline D2-I & -4.92 & 246.27 & $54,48,42$ & Stacking, H-bonding \\
\hline $\mathrm{D} 2-\mathrm{Bt}$ & -5.06 & 194.22 & $54,38,40$ & Stacking \\
\hline $\mathrm{D} 2-\mathrm{Bf}$ & -4.79 & 309.43 & $52,36,40$ & Stacking \\
\hline D3-I & -4.54 & 470.67 & $30,34,60$ & Stacking \\
\hline $\mathrm{D} 3-\mathrm{Bt}$ & -4.62 & 409.25 & $32,30,56$ & Stacking \\
\hline $\mathrm{D} 3-\mathrm{Bf}$ & -4.43 & 565.23 & $30,30,52$ & Stacking \\
\hline
\end{tabular}

Table 10 Docking score values and mean values of binding energy for medical fragments [37]

\begin{tabular}{llll}
\hline Drug & $\begin{array}{l}\text { Medical } \\
\text { fragments }\end{array}$ & $\begin{array}{l}\text { Docking } \\
\text { score }\end{array}$ & $\begin{array}{l}\text { Mean value } \\
\text { of binding } \\
\text { energy }\end{array}$ \\
\hline $\begin{array}{l}\text { Almotriptan, Eletriptan, } \\
\text { Naratriptan, Rizatriptan, }\end{array}$ & I & 6.23 & -4.503 \\
$\begin{array}{l}\text { Sumatriptan, Zolmitriptan } \\
\text { Raloxifene }\end{array}$ & Bt & 7.9 & -4.53 \\
Befunolol & Bf & 5.9 & -4.353 \\
\hline
\end{tabular}

DNA base complexes and the magnitude of the binding energies have been performed. Binding energy parameter allows us to determine if the drug to be prepared can form stable complexes with DNA bases or not. In other words, using this parameter, we can determine its stability before doing experimental work and cost on the drug design.
2. In addition to binding energy, by using AIM results, we can show that the strongest interaction between the drug and the DNA bases from which position are performed, and in the design of the drug by the experimental method, the mechanism has been conducted by the calculation results, so that we have the best design for the drug. Similar to our work, Badichi Akher and coworkers [33] investigated the $\pi$-stacking interactions between aromatic amino acids and quercetagetin (one of the most representative flavonol compounds with biological and chemical activities) using AIM analysis and they found that the ring $\mathrm{C}$ in quercetagetin is more suitable than the rings $\mathrm{A}$ and $\mathrm{B}$ for interaction.

3. Since the empirical study of functional groups effects on the drug fragment properties is more expensive and time-consuming, therefore using quantum mechanics calculations, AIM results, and NBO charge analysis providing more effective drugs for special applications.

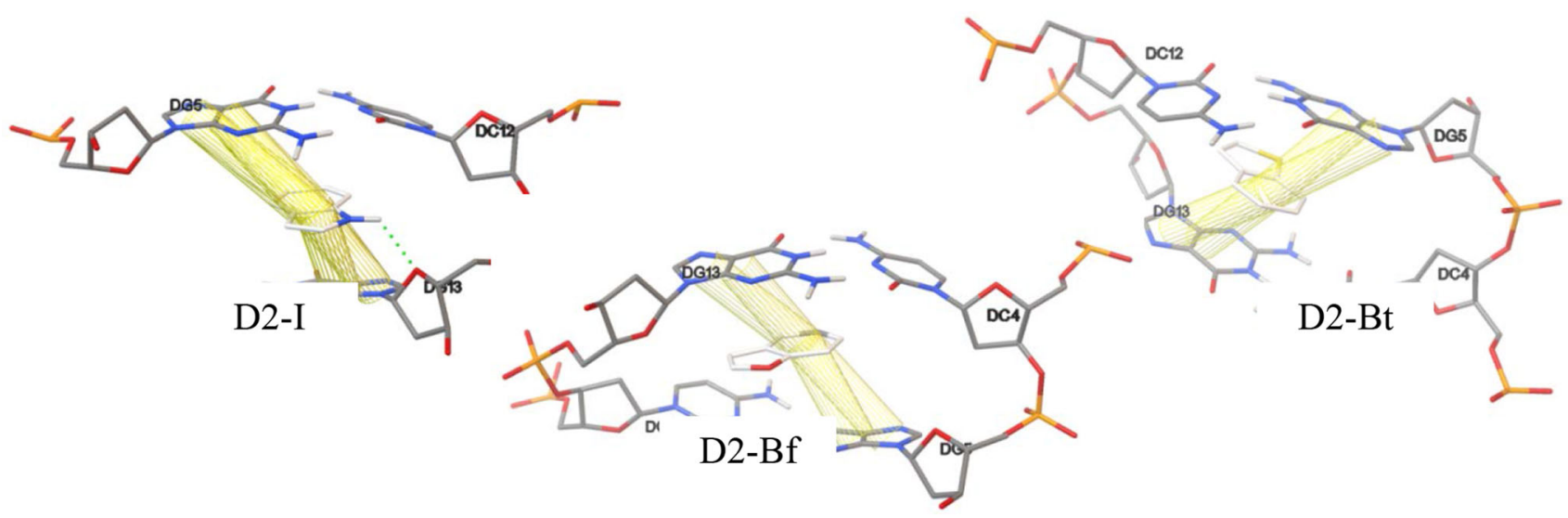

Fig. 8 Interaction between DNA and three drug fragments by AutoDock software 
Acknowledgments Authors are very indebted to Research Committee of the University of Sistan and Baluchestan due to its authorities for financial support during the tenure of which work was completed.

\section{References}

1. Bradley DDC (2014) Organic electronics and photonics: concluding remarks. Faraday Discuss 174:429-438

2. Kool ET (2001) Hydrogen bonding, base stacking, and steric effects in DNA replication. Annu Rev Biophys Biomol Struct 30:1-22

3. Muraki M (2002) The importance of $\mathrm{CH} / \pi$ interactions to the function of carbohydrate binding proteins. Protein Peptide Lett 9:195-209

4. Burley SK, Petsko GA (1985) Aromatic-aromatic interaction: a mechanism of protein structure stabilization. Science 229:23-28

5. Meyer EA, Castellano RK, Diederich F (2003) Interactions with aromatic rings in chemical and biological recognition. Angew Chem Int Ed 42:1210-1250

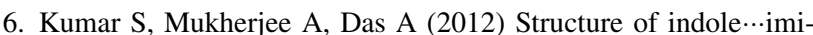
dazole heterodimer in a supersonic jet: a gas phase study on the interaction between the aromatic side chains of tryptophan and histidine residues in proteins. J Phys Chem A 116:11573-11580

7. Hunter CA, Singh J, Thornton JM (1991) $\pi-\pi$ interactions: the geometry and energetics of phenylalanine-phenylalanine interactions in proteins. J Mol Biol 218:837-846

8. Rutledge LR, Campbell-Verduyn LS, Hunter KC, Wetmore SD (2006) Characterization of nucleobase-amino acid stacking interactions utilized by a DNA repair enzyme. J Phys Chem B 110:19652-19663

9. Rutledge LR, Campbell-Verduyn LS, Wetmore SD (2007) Characterization of the stacking interactions between DNA or RNA nucleobases and the aromatic amino acids. Chem Phys Lett 444:167-175

10. Huber RG, Margreiter MA, Fuchs JE, von Grafenstein S, Tautermann CS, Liedl KR, Fox T (2014) Heteroaromatic $\pi$ stacking energy landscapes. J Chem Inf Model 54:1371-1379

11. Salonen LM, Ellermann M, Diederich F (2011) Aromatic rings in chemical and biological recognition: energetics and structures. Angew Chem Int Ed 50:4808-4842

12. Neidle, S (2008) Principles of nucleic acid structure. Elsevier, New York (Chapter 6)

13. Řeha D, Kabeláč M, Ryjáček F, Šponer J, Šponer JE, Elstner M, Suhai S, Hobza P (2002) Intercalators. 1. Nature of stacking interactions between intercalators (ethidium, daunomycin, ellipticine, and 4',6-diaminide-2-phenylindole) and DNA base pairs. ab initio quantum chemical, density functional theory, and empirical potential study. J Am Chem Soc 124:3366-3376

14. Brana MF, Cacho M, Gradillas A, Pascual-Teresa B, Ramos A (2001) Intercalators as anticancer drugs. Curr Pharm Des 7:1745-1780

15. Brovarets OHO, Yurenko YP, Hovorun DM (2015) The significant role of the intermolecular $\mathrm{CH} \cdots \mathrm{O} / \mathrm{N}$ hydrogen bonds in governing the biologically important pairs of the DNA and RNA modified bases: a comprehensive theoretical investigation. J Biomol Struct Dyn 33:1624-1652

16. Calladine CR, Drew HR (1992) Understanding DNA. Academic Press, London

17. Saenger W (1984) Principles of nucleic acid structure. Springer, New York, pp 132-140

18. Wakelin LPG (1986) Polyfunctional DNA intercalating agents. Med Res Rev 6:275-340
19. Desiraju GR, Gavezzotti A (1989) From molecular to crystal structure; polynuclear aromatic hydrocarbons. J Chem Soc Chem Commun 10:621-623

20. Burley SK, Petsko GA (1988) Weakly polar interactions in proteins. Adv Protein Chem 39:125-189

21. Suzuki M, Amano N, Kakinuma J, Tateno M (1997) Use of a 3D structure data base for understanding sequence-dependent conformational aspects of DNA1. J Mol Biol 274:421-435

22. Burkard ME, Kierzek R, Turner DH (1999) Thermodynamics of unpaired terminal nucleotides on short RNA helixes correlates with stacking at helix termini in larger RNAs1. J Mol Biol 290:967-982

23. Wu P, Nordlund TM, Gildea B, McLaughlin LW (1990) Base stacking and unstacking as determined from a DNA decamer containing a fluorescent base. Biochemistry 29:6508-6514

24. Swart M, van der Wijst T, Fonseca Guerra C, Bickelhaupt FM (2007) $\pi-\pi$ stacking tackled with density functional theory. J Mol Model 13:1245-1257

25. Gu J, Wang J, Leszczynski J, Xie Y, Schaefer Iii HF (2008) To stack or not to stack: performance of a new density functional for the uracil and thymine dimers. Chem Phys Lett 459:164-166

26. Cysewski P, Czyżnikowska-Balcerak Ż (2005) The MP2 quantum chemistry study on the local minima of guanine stacked with all four nucleic acid bases in conformations corresponding to mean B-DNA. J Mol Struct (Thoechem) 757:29-36

27. Cysewski P, Czyżnikowska-Balcerak Ż (2007) A post-SCF quantum chemistry study on local minima of 8-oxo-guanine stacked with all four nucleic acid bases in B-DNA conformations. J Heterocycl Chem 44:765-773

28. Sharma V, Kumar P, Pathak D (2010) Biological importance of the indole nucleus in recent years: a comprehensive review. J Heterocycl Chem 47:491-502

29. Vicente R (2011) Recent advances in indole syntheses: new routes for a classic target. Org Biomol Chem 9:6469-6480

30. Khanam H, Uzzaman S (2015) Bioactive Benzofuran derivatives: a review. Eur J Med Chem 97:483-504

31. Ferreira AP, da Silva JLF, Duarte MT, da Piedade MFM, Robalo MP, Harjivan SG, Marzano C, Gandin V, Marques MM (2009) Synthesis and characterization of new organometallic benzo[b]thiophene derivatives with potential antitumor properties. Organometallics 28:5412-5423

32. Queiroz M-JRP, Ferreira ICFR, Gaetano YD, Kirsch G, Calhelha RC, Estevinho LM (2006) Synthesis and antimicrobial activity studies of ortho-chlorodiarylamines and heteroaromatic tetracyclic systems in the benzo[b]thiophene series. Bioorg Med Chem 14:6827-6831

33. Akher FB, Ebrahimi A, Mostafavi N (2017) Characterization of p-stacking interactions between aromatic amino acids and quercetagetin. J Mol Struct 1128:13-20

34. Schneider H-J (2009) Binding mechanisms in supramolecular complexes. Angew Chem Int Ed 48:3924-3977

35. Dougherty DA (1996) Cation-pi interactions in chemistry and biology: a new view of benzene, Phe, Tyr and Trp. Science 271:163-168

36. Harder M, Kuhn B, Diederich F (2013) Efficient stacking on protein amide fragments. ChemMedChem 8:397-404

37. Wallnoefer HG, Fox T, Liedl KR, Tautermann CS (2010) Dispersion dominated halogen-[small pi] interactions: energies and locations of minima. Phys Chem Chem Phys 12:14941-14949

38. Janiak C (2000) A critical account on [small pi]-[small pi] stacking in metal complexes with aromatic nitrogen-containing ligands. J Chem Soc, Dalton Trans 21:3885-3896

39. Snyder RD, Holt PA, Maguire JM, Trent JO (2013) Prediction of noncovalent Drug/DNA interaction using computational docking 
models: studies with over 1350 launched drugs. Environ Mol Mutagen 54:668-681

40. Trucks GW, Frisch MJ, Schlegel HB, Scuseria GE, Robb MA, Cheeseman JR, Scalmani G, Barone V, Petersson GA, Nakatsuji H, Li X, Caricato M, Marenich A, Bloino J, Janesko BG, Gomperts R, Mennucci B, Hratchian HP, Ortiz JV, Izmaylov AF, Sonnenberg JL, Williams-Young D, Ding F, Lipparini F, Egidi F, Goings J, Peng B, Petrone A, Henderson T, Ranasinghe D, Zakrzewski VG, Gao J, Rega N, Zheng G, Liang W, Hada M, Ehara M, Toyota K, Fukuda R, Hasegawa J, Ishida M, Nakajima T, Honda Y, Kitao O, Nakai H, Vreven T, Throssell K, Montgomery JA Jr, Peralta JE, Ogliaro F, Bearpark M, Heyd JJ, Brothers E, Kudin KN, Staroverov VN, Keith T, Kobayashi R, Normand J, Raghavachari K, Rendell A, Burant JC, Iyengar SS, Tomasi J, Cossi M, Millam JM, Klene M, Adamo C, Cammi R, Ochterski JW, Martin RL, Morokuma K, Farkas O, Foresman JB, Fox DJ (2009) Gaussian 09 Citation

41. Boys SF, Bernardi F (1970) The calculation of small molecular interactions by the differences of separate total energies. Some procedures with reduced errors. Mol Phys 19:553-566

42. Zhao Y, Truhlar DG (2008) The M06 suite of density functionals for main group thermochemistry, thermochemical kinetics, noncovalent interactions, excited states, and transition elements: two new functionals and systematic testing of four M06 functionals and 12 other functionals. Theoret Chem Acc 119:525

43. Wheeler SE, Bloom JWG (2014) Toward a more complete understanding of noncovalent interactions involving aromatic rings. J Phys Chem A 118:6133-6147

44. Riley KE, Hobza P (2011) Noncovalent interactions in biochemistry. Wiley Interdiscip Rev Comput Mol Sci 1:3-17

45. Reed AE, Curtiss LA, Weinhold F (1988) Intermolecular interactions from a natural bond orbital, donor-acceptor viewpoint. Chem Rev 88:899-926

46. Bader RFW (1990) Atoms in molecules: a quantum theory. Clarendon Press, Oxford

47. Biegler-Konig F, Schonbohm J, Bayles D (2001) AIM2000. J Comput Chem 22:545-559

48. Breneman Curt M, Wiberg Kenneth B (1990) Determining atomcentered monopoles from molecular electrostatic potentials. The need for high sampling density in formamide conformational analysis. J Comput Chem 11:361-373

49. Morris GM, Huey R, Lindstrom W, Sanner MF, Belew RK, Goodsell DS, Olson AJ (2009) AutoDock4 and AutoDockTools4: automated docking with selective receptor flexibility. J Comput Chem 30:2785-2791

50. http://www.rcsb.org/pdb/home/home.do 